\title{
Atrium Politic / The Lost Models of Oversight in Semi-Public Space of Roman Antiquity
}

\author{
JONATHAN A. SCELSA
}

Pratt Institute + American Academy in Rome

The agency of the edge condition of public and private space, can be felt strongly in its ability to create personal, programmatic and spatial ambiguity. It is for this reason that semi-public space, during times of political and social shift, is the most precarious and vulnerable.

Providing a means of oversight that our state-craft has lost, the atrium's role as a juridical space was implemented within the work-life heart of the various members of public service, from senators, to religious and cult practices. While the atrium's notoriety has been in its section, its politic is embedded in the plan relationship of its walls informing a technology of power and a smooth gradient threshold between the potentially abusive power of private domain and the all-seeing realm of the street.

\section{WALL AS PRIVACY}

Fundamental to the argument of this essay, is the agency of the architectural element of the wall, to render the occurrences within a cellularized space as opaque to the outer world. This concept has been well explored in Michel Foucalt's work, who has focused on the ideas of overcoming of secrecy through the arrangement of architecture walls as a 'technology of power.' in other words, that the un-camouflaged visibility of the body through wall and aperture arrangements, increases the possibility of surveillance and is directly proportional with levels of control. thus informing a definition of privacy as the control of other's knowledge of oneself. More visibility leads to more power over a thing ${ }^{1}$. While this is a very simple notion, it cannot go understated in a contemporary world, through which we have accepted that it is digital media as the enabling technology of power in the place of architectural exposure and assignment.

John Locke in his essay, Concerning Human Understanding, describes the 17th century camera obscura chamber as an observable act of judgement for the spectator at a period when the many devices such as printed press were emerging for mass edification. Within the chamber, a viewer would witness the light from the outside carrying the image of the outer world onto the surfaces of the room allowing an artist to trace with accuracy a drawing. The significance of this is Locke synchronizes a space with the act of subject-object observance creating a juridical role, allowing the public to occupy the edified chair as witness to the occurrence in the same manner as a judge's chamber, wherein the public would be present for the edict of the law. If we come to understand the arrangement of the wall as technology of power we can understand that thresholds for entry and view can be an analog for light and drawing. ${ }^{2}$

\section{ATRIUM AS SEMI - PUBLIC}

In Roman antiquity, atria existed as defined spaces, albeit often with gray borders at two scales of implementation, both at shared scale of the city as well as at the scale of the individual domestic within houses of state and mercantile leadership. Notably in both cases the atrium was formed as a quasi indoor - outdoor space with some overhead framed view of the sky, within a semi-enclosed environment that maintained open-access. (Access should be qualified in this case as both view-shed access and physical and tangible ability to move within and in between the various programs of the surrounding architecture). It is notable that in antiquity there was a radical different notion of public - private space, wherein no space could be examined as as solely or fully public. All spaces perceived as 'for the people' served some form of other municipal duty whether it be sacred, or political. As a gray zone the atria, established a pronounced gray-zone or space gradient between that which was individual and that which as shared. Examples of which might be the religious cult spaces of the elected officials of the vestae on the forum to domestic homes of members of the government. ${ }^{3}$

One of the natures of the Roman Republic was a scattered work-force where artisans, and senators each maintained their own practice within their homes. As a result during republican rule, two centers would be employed within the home. The first, the atrium was an extension of the Roman market and road, axially bleeding into the home as a space of connection and commerce. the second, the peristylium, hellenistically borrowed from the greek polis as place of debate, became the center of life within the home as an external garden. ${ }^{4}$

These centers typologically varying in size, would be employed in families of the merchant class and the senatorial class, as well as in the smaller scale houses of the poor, albeit scaled down with similar planometric rules. This practice of work-life was instrumentalized in the physical spatial makeup of the roman home, by use of the semi-public indoor-outdoor audience chamber of the atria which occupied a position within the entry-way of roman domus. This atrium informed the center of the Roman public life within the home and the space of salutatio, a practice wherein the merchant owner or 


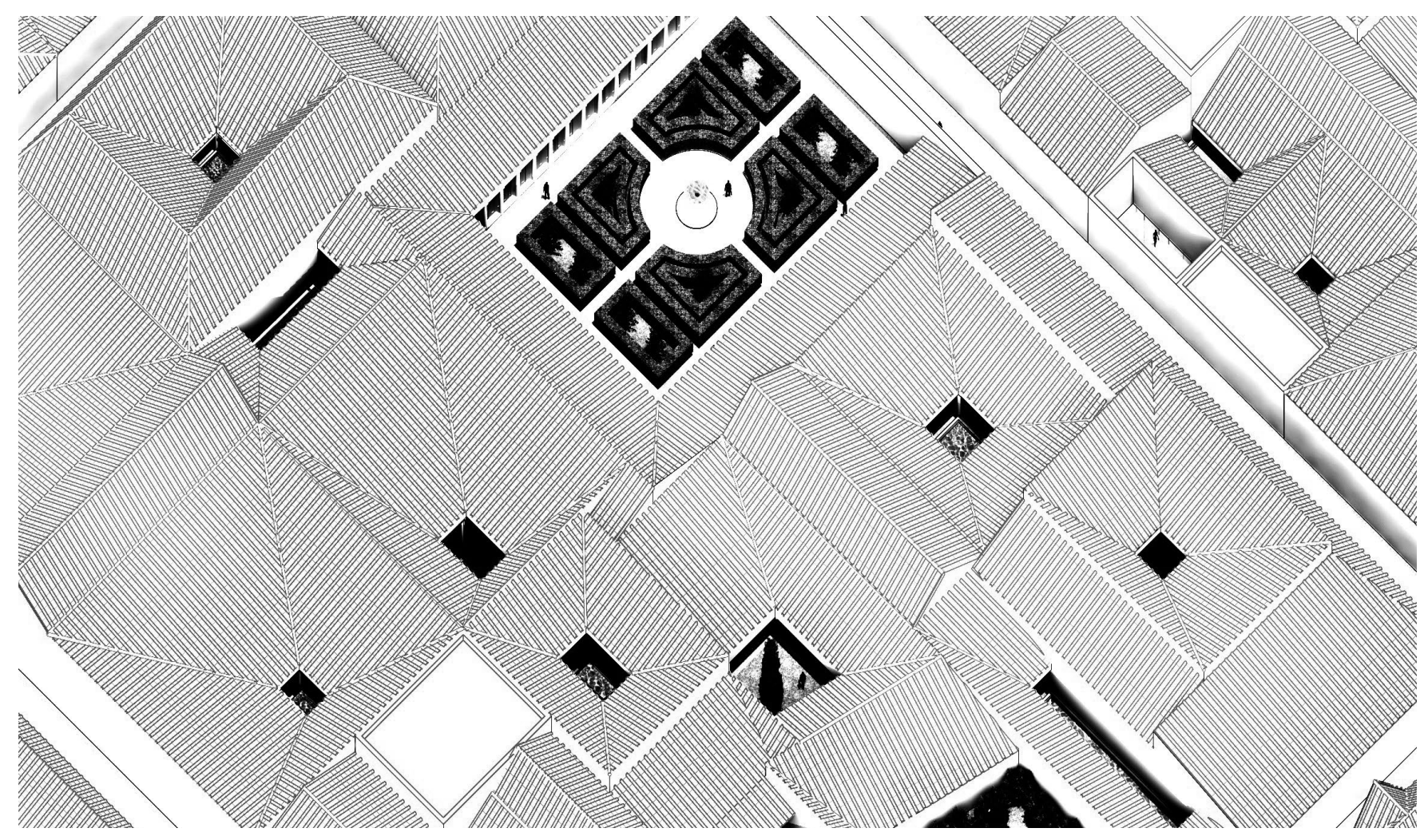

Figure 1: The atrium and Peri-style within the field of the Roman City.

governmental patrician would be available each morning by law to greet petitioners from the street (figure 3 / Explosion).

The second space was the peristylium, a formal a garden courtyard with a surrounding columnated portico often implemented to the rear of the home from the street, axially visible from the street. Where open-air conversations would be had between senators, centered between the two worlds would be the tablinum, or owner's office, capable of observing both. The atrium, connected directly to the street through the open corridor or fauces, serving as an extension of the public spaces of the forum and the market within the home. This architectural arrangement imbued these twin internal worlds with a juridical aspect for the populace and several laws were implemented to ensure the maintenance of the domestic architecture's physical capacity for accommodating this social role.

\section{VISIBLE OVERSIGHT}

For the ancient world, it could be maintained that the atrium acted as an urban juridical device, both in its ability to bring individuals in, allowing them to become witness observers, but also in the way it endemically presents a symbolic space of the republic's principles of representation. Herein we see that many rooms of dining and the alae were directly accessible to the public as they moved into house during salutatio, extending the visual watch of political praxis.
Notably, oversight is not only given by those from outside the house but also those from within. The atrium is effective in this means as well as a room through which all parties would cross, inclusive of owners, servants, families, outsider and spouses. Thereby all these parties maintain physical access to each other in order to conduct their varied internal domestic jobs and business. The atrium controls that access. Mark Grahame in his essay, Public and private in the Roman house, establishes a particular metric for measuring that very condition dubbing a control value for each space of a home, based on its ability access to other spaces. This concept of controlled shared access is seen here, where this circuit diagram and the justified corollary demonstrate, what is already obvious, that the atrium serves all of the spaces in physical access simultaneous to visual access. In this case, the atrium has a control value of 14 as it controls 14 spaces, and notably in this case that control is given to those who can enter the house. When we extend this diagram to the entirety of a much larger and multi-centric situation, such as the House of the Faun in Pompeii, we see again the dominance in the circuit diagram of the atria and peristylium. Particularly demonstrating their ability to both act as controllers within the house, as well access to the street. Here we see that rather than rooms and sub-rooms as would be evident in a palace plan or a corridor scheme, all rooms are only 1 or 2 steps removed from the public - sphere and have direct and intermingled shared access to the programmed spaces (figure 4 / Circuit Board Diagrams 

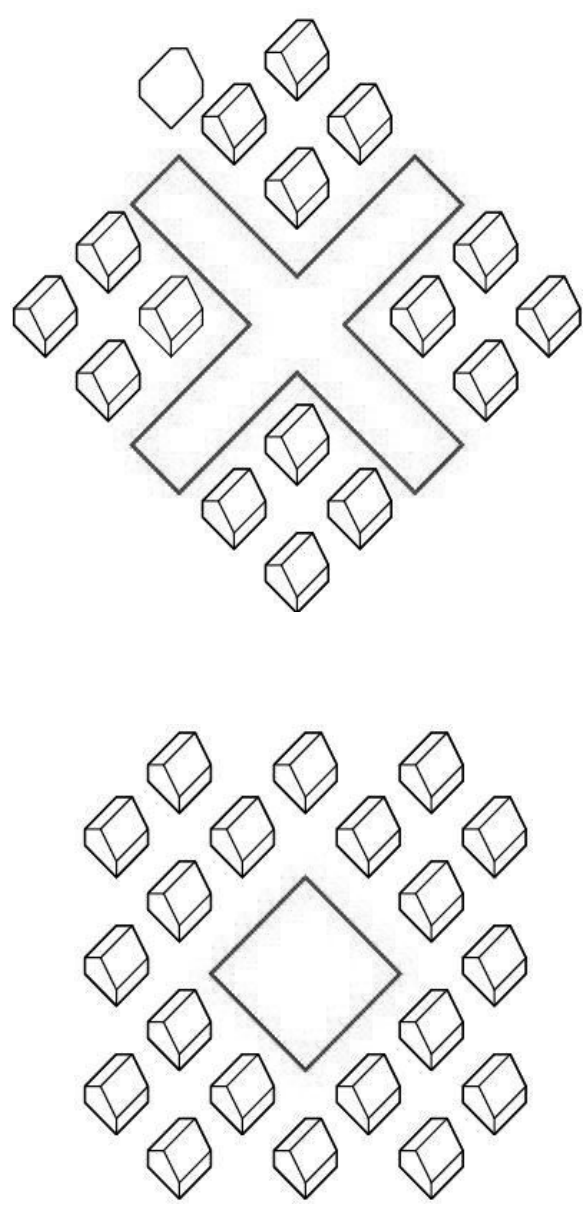

Figure 2: Saskatchewan Power Corporation Head Office Building, c.2000 after being re-clad in aluminum metal panels, SaskPower Archives.

Compiled). The demonstration of this diagrammatic method is definably planometric in focus and supports recent scholarship that disintegrates the distinction between the formal and sectional open-compluviate atrium house and the other Roman types of the row house as both contain commonalities in how the two perform socially and planometrically due to their arrangement around central spaces of salutation. This also raises the importance of the other elements such as the rear peristylium within the rhizomatic plan, as central controllers and not merely rear garden.

Compare the open atria of these senate houses, wherein a few steps through the fauces grants programmatic visibility, to a sample political project of Rome's imperial era following the fall of the republic. Here the golden palace of Nero evinces a centrally planned palace the public was able to witness via the entry court. Through its bulk and extended linear axis with the beginnings of corridor employment, the decision making and political activities are displaced to the privatized rooms of the outer wings, rendered opaque to the public. And if the scale of Nero's opulence might be dismissed as low hanging fruit of problematic domestic political space, there exists a litany of other examples of cloistered typologies offered under the American political built establishment predicated on its original principles.

This wing plan arguably became the basis for a neo-classical understanding of both the villa of nobility and later political land governor, pushing forward a symbolic fore-court grand space that is neutered in potency from the original atrium's visual and public access. The villa model of statehood, most prevalent within the executive branch's Palladian neo-classical language, as well as typological equivalences to Mar-a-Lago and the White House, systematically displaces the public towards a gestured sense of entry grandeur, obliterating the juridical observed space of salutation. (figure 5 / House of Faun, Villa Barbaro, Nero Comparison).

\section{ARCHITECTURAL ILLUSION AS A SUBVERSIONARY TACTIC}

Decoration of the home provides much evidence on why the atrium was considered public space, specifically in its content and quantity. It is notable that while the use of publicus and privatus were not extensively used words, several occasions these were used to describe how space should be adorned and treated. Cicero, Sallust and Pliny were notorious for attacking the use of high decoration and luxurious materials within the private space of the home, while championing its use within the forum where all could enjoy. A notable exception of which, according to Cicero's De Officiis, would be in the house of a public official or leader as a space of salutation.

Further evidence on the efficacy of these spaces as controllers through surveillance and access might be seen in the illusionary decorative impulses. During the time-period as means of subverting the open surveilled plan, in favor of a confusion and opulent camouflage. The decorative principals within these spaces, particularly during the age of the republic, was centered around the illusionistic decorative practice of the second or architectural style. The second style emerged during the height of the Roman republic leading up to its decline into the imperial, notable for its studious drawing practice of early antique perspective, that was aimed at de-materializing the physicality of the wall through references to exterior garden spaces of the peri-style imbued by the Hellenistic appeal of the Greeks.

Andrew Wallace-Hadrilll has drawn attention to the synchronicity of these opulent architectural illusions within the most accessible public spaces, demonstrating a parlor trick in the space of the rooms open to the public. Wallace-Hadrill's suggestion is that these illusions are in fact indicators of the spaces most associated with public space in the minds of the residence due to their opulence. An alternative argument 


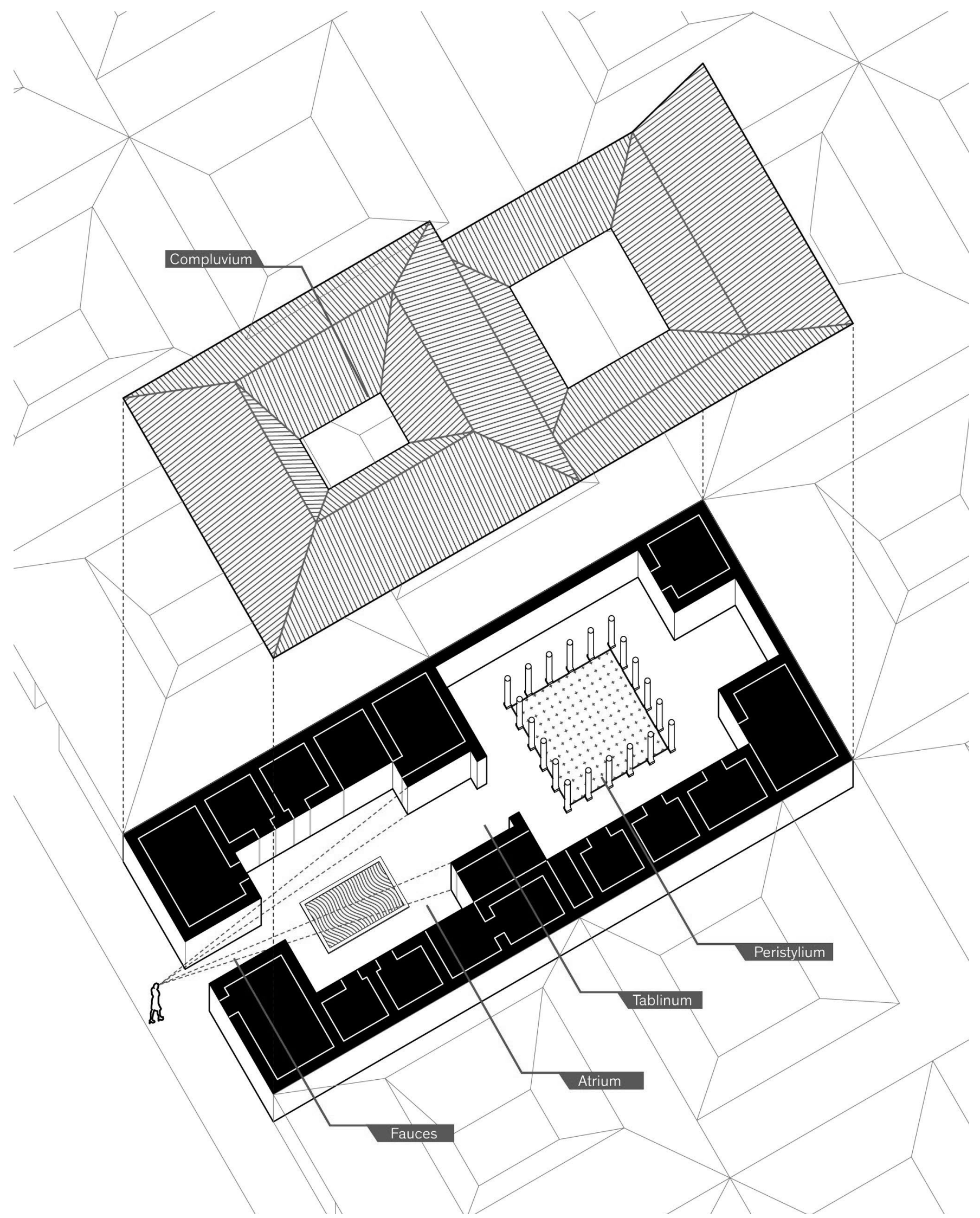

Figure 3: The visual oversight axis of the Roman Domus and its typological room arrangement 


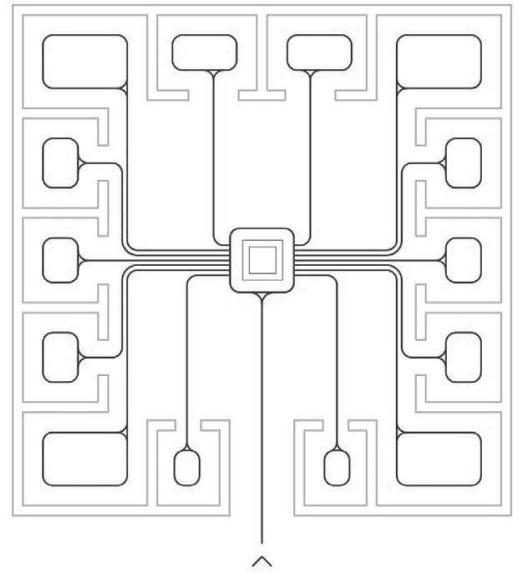

ACCESS DIAGRAM

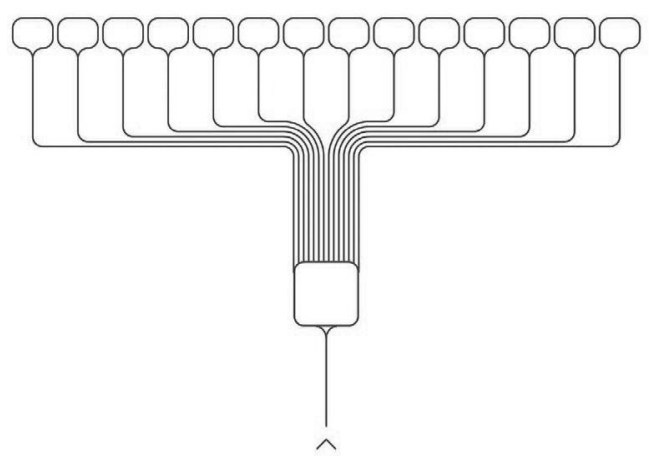

CIRCUIT BOARD CONTROL DIAGRAM

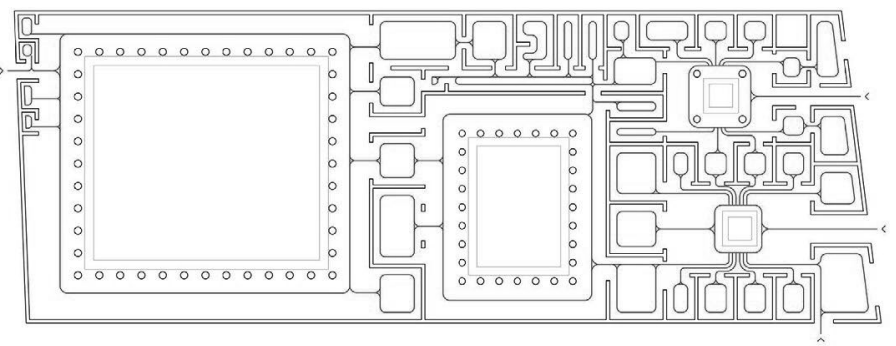

ACCESS DIAGRAM

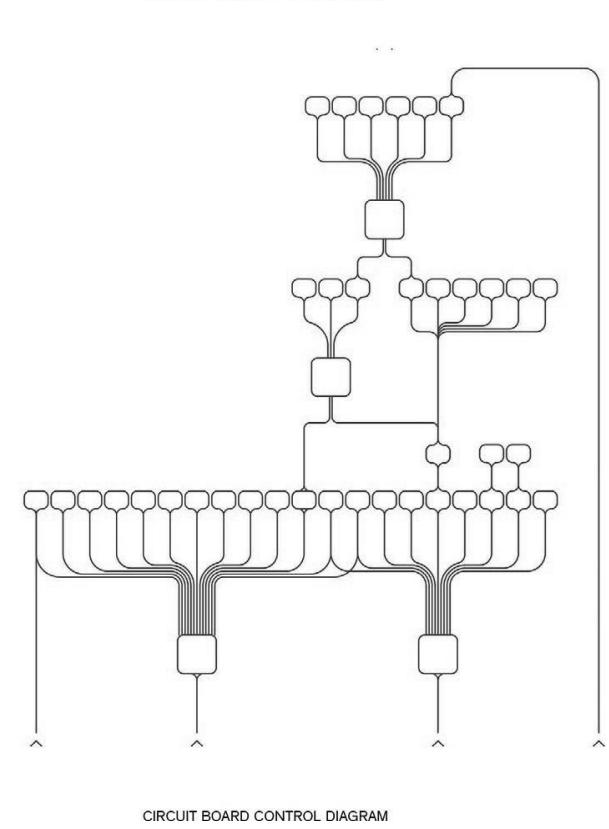

Figure 4 Circuit Board Diagram reproduced from Mark Grahame.

that is also complementary to the conclusion, suggests that the surveillance within the plan of the Roman house was so efficient and the typological nature of the house so enduring in the mental image of the residents that the decorative potential became in confusing the eye and creating a sense of mystery and false privacy, and spatial subterfuge by the artist's and patrons. Support for this might be witnessed within the subject matter of the actual canvas. Often, as in the case in the Villa Poppea of Opplontis, the wall-image references the very room upon which it is painted though it is pushed backwards in space, and surrounded by a fictional garden. Thus the space of the meeting is objectified by creating a walled-privacy perimeter. Several art historians have noted the visual and cultural change to Rome following the Republic under the Imperial Rule of Augustus, whom pushed for "the moral turn-around" during which "the illusion of breaking through the wall is no longer sought - rather its integrity is emphasized - and the viewer is meant to focus on the meaning of just a few images that dominate the room." This break from the interest in speculative unreal or hedonistic fantastic practice, could also be argued to a simplification and a return to the physical architecture of a surveilled world within the realm of the atrium. With the neutered power of the senate and the mercantile class under imperial regime there was decided less need for privacy, particularly within the change of state-hood.

\section{CONTEMPORARY STATE-CRAFT}

Perhaps most problematic of all would be to compare the Roman model to the 'the best architecture' offered on 5th Avenue as the state of political spatial arrangements present in the world of contemporary state-craft. A direct formal analogy suggesting that Trump Tower's ground floor "over-sized sectional atrium - lobby" as the modern day fauces, while 

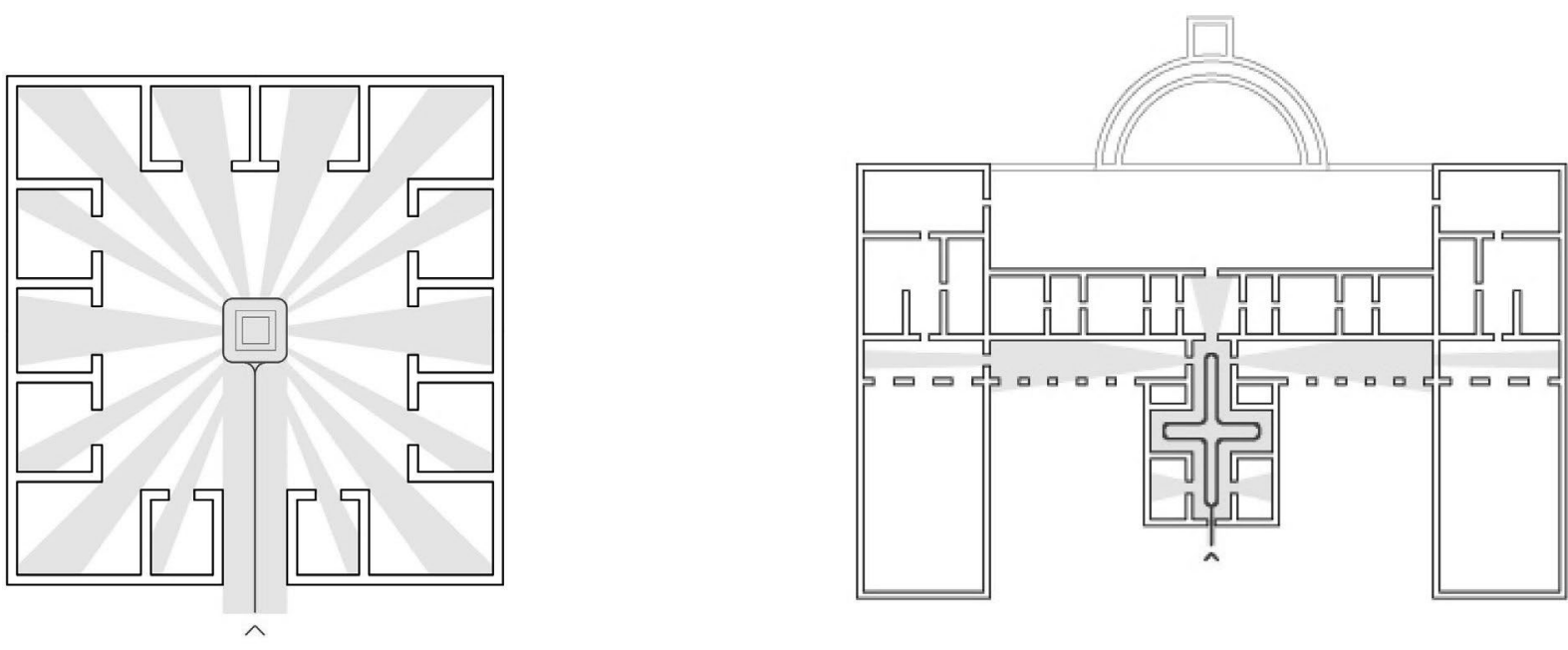

ROMAN COMPIINIATF ATRIIIM

VII I A RARRARO

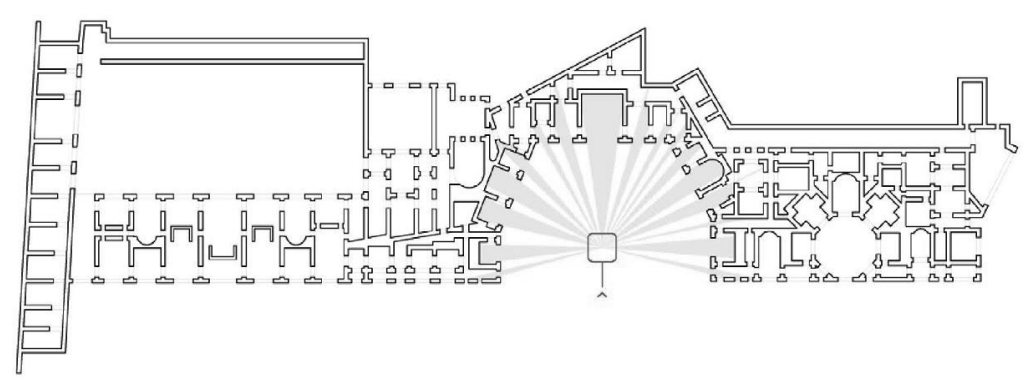

DOMUS AUREA / NERO'S PALACE

the equivalent to the Roman atrium, the space of salutatio for greeting and business transaction, would be on the 56th floor. The elevator in this case deliriously severing the 'domain of the deal' from the space of public oversight that would have been granted by visual axis of the fauces through the atrium, tablinum and peristylium. While somewhat tongue and cheek, this paper seeks to unpack the spatial morphology of the Roman antiquity space of salutatio as a space of semi-public nature to the security controlled political space of today, disabling the possibility of architectural oversight.

\section{ENDNOTES}

1. A. Giddens, The Constitution of Society; Outline of a Theory of Structuration (Cambridge 1984), 129.

2. Jonathan Crary, Techniques of the Observer: On Vision and Modernity in the Nineteenth Century (Cambridge, MA: MIT Press, 2012).

3. Amy Russell, The Politics of Public Space in Republican Rome (Cambridge: Cambridge University Press, 2016).

4. Jamie Sewell, The Formation of Roman Urbanism, 338-200 B.C.: Between Contemporary Foreign Influence and Roman Tradition (Portsmouth, Rl: Journal of Roman Archaeology, 2010).
5. Mark Grahame, "Public and Private in the Roman House," Journal of Roman Archaeology 22 (1997): 148

6. Andrew Wallace-Hadrill, "Re-Thinking the Roman Atrium House," Journal of Roman Archaeology 22 (1997): 222

7. Russell. The Politics of Public Space in Republican Rome, 8.

8. Paul Zanker, The Power of Images in the Age of Augustus (Ann Arbor: University of Michigan Press, 2002). 